\title{
Impact of World Health Organization (WHO) new standards on the referral pattern of infertile men for assisted reproduction
}

\author{
Saad Alshahrani ${ }^{1,2}$, Ashok Agarwal ${ }^{1,3^{*}}$, Mourad Assidi ${ }^{3,4}$, Adel M. Abuzenadah ${ }^{3,4}$, Damayanthi Durairajanayagam ${ }^{1,5}$, \\ Ahmet Ayaz', Rakesh Sharma'
}

From 2nd International Genomic Medical Conference (IGMC 2013)

Jeddah, Kingdom of Saudi Arabia. 24-27 November 2013

\section{Background}

New reference values for semen parameters are significantly lower in the WHO 5th edition (2010) than in the 4th edition [1,2]. Some of the highlights of the fifth edition were: 1 ) subjects included in this edition had $<12$ months' time to pregnancy, 2) semen analyses results were pooled and analyzed for reference values, 3) laboratories generating the data used standardized methods for semen analysis according to WHO manual available at the time of original studies and 4) one-sided lower reference limits (5th centile) were generated and proposed as lower cut-off limits for normal values. The new reference values were aimed at providing evidencebased thresholds to assist clinicians in calculating relative fertility of the patient. The goal of our study was to examine the impact of the new WHO reference values on the referral pattern of infertile men referred for assisted reproduction (IUI, IVF/ICSI).

\section{Materials and methods}

In this study, we examined the medical records of 362 infertile, non-azoospermic men referred to the Andrology laboratory between 2011 and 2012. Patients were divided into 2 groups; Group A: patients evaluated in 2011 by the
WHO 4th edition $(\mathrm{n}=200)$ [1] and Group B: patients evaluated in 2012 by the WHO 5th edition $(\mathrm{n}=162)$ [2]. All patients were examined for conventional semen parameters including sperm morphology. The number of total referrals for IUI or IVF/ICSI was recorded. ART outcomes were not evaluated in this study.

\section{Results}

A significant decline in the number of IVF/ICSI referrals was seen $(71.5 \%$ vs. $53.1 \%$; $\mathrm{P}<0.05)$ as well as the number of patients with abnormal sperm morphology declined significantly $(76.5 \%$ vs. $30.9 \%$; $\mathrm{P}<0.05)$ with the introduction of new reference values for semen analysis (WHO 5th edition). In cases referred for ART, abnormal sperm morphology was documented in 107 patients in Group A (74.8\%) versus $23(26.7 \%)$ in Group B.

\section{Conclusions}

Reporting of semen parameters based on the new WHO criteria may significantly impact the management of infertile men since more men will be categorized as normal and fewer of them will be referred for ART. This will result in many men postponing additional evaluations or seeking further treatment.

\footnotetext{
* Correspondence: agarwaa@ccf.org

${ }^{1}$ Center for Reproductive Medicine, Cleveland Clinic, Cleveland, Ohio 44195, USA

Full list of author information is available at the end of the article
} 
Table 1 New WHO sperm morphology cutoff and its impact on IUI/ART referrals

\begin{tabular}{|c|c|c|c|c|}
\hline \multirow[t]{2}{*}{ Parameter } & \multicolumn{2}{|c|}{ Group A (WHO $4^{\text {th }}$ Edition) } & \multicolumn{2}{|c|}{ Group B (WHO $5^{\text {th }}$ Edition) } \\
\hline & $\mathbf{n}$ & $\%$ & n & $\%$ \\
\hline Number of patients & 200 & 100 & 162 & 100 \\
\hline WHO Abnormal Sperm Morphology & 153 & 76.5 & 50 & $30.9^{a}$ \\
\hline New referral for IUI/IVF/ICSI & 143 & 71.5 & 86 & $53.1^{a}$ \\
\hline $\mid \mathrm{IUI}$ & 94 & 65.7 & 60 & 70 \\
\hline$\overline{\mid V F / I C S I}$ & 49 & 34.3 & 26 & $30^{\mathrm{a}}$ \\
\hline WHO Abnormal Sperm Morphology among IUI or IVF/ICSI Referrals & 107 & 74.8 & 23 & $26.7^{\mathrm{a}}$ \\
\hline
\end{tabular}

${ }^{\mathrm{a}} P<0.05$ was considered significant by chi-square test

\section{Authors' details}

${ }^{1}$ Center for Reproductive Medicine, Cleveland Clinic, Cleveland, Ohio 44195, USA. ${ }^{2}$ Salman Bin Abdulaziz University, College of Medicine, Saudi Arabia. ${ }^{3}$ Center of Excellence in Genomic Medicine Research, KAU, Saudi Arabia. ${ }^{4}$ KACST Technology Innovation Center for Personalized Medicine at King Abdulaziz University, Jeddah, Saudi Arabia. ${ }^{5}$ MARA University of Technology, Sungai, Selangor Darul Ehsan, Malaysia.

Published: 2 April 2014

\section{References}

1. World Health Organization: WHO laboratory manual for the examination of human semen and sperm-cervical mucus interaction. Cambridge University Press; Fourth 1999

2. World Health Organization: WHO laboratory manual for the examination and processing of human semen. Geneva, Switzerland; Fifth[http://www. who.int/reproductivehealth/publications/infertility/9789241547789/en/].

doi:10.1186/1471-2164-15-S2-P31

Cite this article as: Alshahrani et al:: Impact of World Health

Organization (WHO) new standards on the referral pattern of infertile men for assisted reproduction. BMC Genomics 2014 15(Suppl 2):P31.

Submit your next manuscript to BioMed Central and take full advantage of:

- Convenient online submission

- Thorough peer review

- No space constraints or color figure charges

- Immediate publication on acceptance

- Inclusion in PubMed, CAS, Scopus and Google Scholar

- Research which is freely available for redistribution

Submit your manuscript at www.biomedcentral.com/submit 